36 Stamler J. Epidemiology, established major risk factors and the primary prevention of coronary heart disease. In: Parmley WW, Chatterjee K, eds. Cardiology. Philadelphia:JB Lippincott, 1987:1-41.

37 UKPDS Group. UK prospective diabetes study 24: relative efficacy of sulfonylurea, insulin and metformin therapy in newly diagnosed non-insulin dependent diabetes with primary diet failure followed for six years. Ann Intern Med 1998;128:165-75.

38 American Diabetes Association. Report of the expert committee on the diagnosis and classification of diabetes mellitus. Diabetes Care 1998;21(suppl 1):5-19.

39 Franklin GF, Shetterly SM, Cohen JA, Baxter J, Hamman RF. Risk factors for distal symmetric neuropathy in NIDDM. The San Luis Valley diabetes study. Diabetes Care 1994:1172-7.

40 Harris M, Eastman R, Cowie C. Symptoms of sensory neuropathy in adults with NIDDM in the US population. Diabetes Care 1993;16:1446-52. 41 Adler AI, Boyko EJ, Ahroni JH, Smith DG. Lower extremity amputation in diabetes mellitus: the independent effects of peripheral vascular disease, sensory neuropathy and foot ulcers. Diabetes Care 1999;22: $1029-35$
42 Adler AI, Matthews D, Holman RR, Turner RC. Type 2 diabetes and death: causes, estimated life expectancy and mortality rates-the UK prospective diabetes study. Diabetes 1998;47(suppl 1):A71.

43 Palumbo PJ, Elveback LR, Chu CP, Connolly DC, Kurland LT. Diabetes mellitus: incidence, prevalence, survivorship and causes of death in Rochester, Minnesota, 1945-1970. Diabetes 1976;25:566-73.

44 Panzram G. Mortality and survival in type 2 (non-insulin-dependent) diabetes mellitus. Diabetelogia 1987;30:123-31.

45 Goodkin G. Mortality in diabetes. A 20 year mortality study. J Occup Med $1975 ; 17: 716-21$.

46 Wetterhall SF, Olson DR, DeStefano F, Stevenson JM, Ford ES, German RR, et al. Trends in diabetes and diabetic complications, 1980-1987. Diabetes Care 1992;15:960-7.

47 Stamler J, Vaccaro O, Neaton JD, Wentworth D. Diabetes, other risk factors, and 12 year cardiovascular mortality for men screened in the multiple risk factor intervention trial. Diabetes Care 1993;16:434-44.

(Accepted 20 March 2000)

\title{
Association of systolic blood pressure with macrovascular and microvascular complications of type 2 diabetes (UKPDS 36): prospective observational study
}

\author{
Amanda I Adler, Irene M Stratton, H Andrew W Neil, John S Yudkin, David R Matthews, \\ Carole A Cull, Alex D Wright, Robert C Turner, Rury R Holman on behalf of the UK Prospective \\ Diabetes Study Group
}

Editorial by
Tuomilehto

Diabetes Trial Unit Oxford Centre for

Diabetes,

Endocrinology and

Metabolism,

University of

Oxford, Radcliffe

Infirmary, Oxford

OX2 6HE

Amanda I Adler epidemiologist

Irene M Stratton

senior statistician

Carole A Cull

senior statistician

Rury R Holman

director

Division of Public

Health and Primary

Care, Institute of

Health Sciences,

University of

Oxford, OX3 7LF

$\mathrm{H}$ Andrew W Neil

university lecturer in

clinical epidemiology

continued over

BMJ 2000;321:412-9

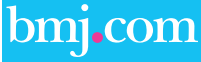

Details of participating centres, staff, and committees and additional funding agencies are on the BMJ's website

\section{Abstract}

Objective To determine the relation between systolic blood pressure over time and the risk of macrovascular or microvascular complications in patients with type 2 diabetes.

Design Prospective observational study. Setting 23 hospital based clinics in England, Scotland, and Northern Ireland.

Participants 4801 white, Asian Indian, and Afro-Caribbean UKPDS patients, whether randomised or not to treatment, were included in analyses of incidence; of these, 3642 were included in analyses of relative risk.

Outcome measures Primary predefined aggregate clinical outcomes: any complications or deaths related to diabetes and all cause mortality. Secondary aggregate outcomes: myocardial infarction, stroke, lower extremity amputation (including death from peripheral vascular disease), and microvascular disease (predominantly retinal photocoagulation). Single end points: non-fatal heart failure and cataract extraction. Risk reduction associated with a $10 \mathrm{~mm}$ $\mathrm{Hg}$ decrease in updated mean systolic blood pressure adjusted for specific confounders

Results The incidence of clinical complications was significantly associated with systolic blood pressure, except for cataract extraction. Each $10 \mathrm{~mm} \mathrm{Hg}$ decrease in updated mean systolic blood pressure was associated with reductions in risk of $12 \%$ for any complication related to diabetes $(95 \%$ confidence interval $10 \%$ to $14 \%, \mathrm{P}<0.0001), 15 \%$ for deaths related to diabetes ( $12 \%$ to $18 \%, \mathrm{P}<0.0001), 11 \%$ for myocardial infarction ( $7 \%$ to $14 \%, \mathrm{P}<0.0001)$, and $13 \%$ for microvascular complications $(10 \%$ to $16 \%$, $\mathrm{P}<0.0001)$. No threshold of risk was observed for any end point.
Conclusions In patients with type 2 diabetes the risk of diabetic complications was strongly associated with raised blood pressure. Any reduction in blood pressure is likely to reduce the risk of complications, with the lowest risk being in those with systolic blood pressure less than $120 \mathrm{~mm} \mathrm{Hg}$.

\section{Introduction}

The UK prospective diabetes study (UKPDS) has shown that a policy of tight control of blood pressure, which achieved a median blood pressure of 144/82 mm Hg compared with 154/87 mm Hg over median 8.4 years of follow up, substantially reduced the risk of microvascular disease, stroke, and deaths related to diabetes, ${ }^{1}$ but not myocardial infarction. Complementary information for estimates of the risk of complications including myocardial infarction at different levels of blood pressure can be obtained from observational analysis of the UKPDS data. This information can help to estimate the expected reduction in the risk of diabetic complications from a given change in blood pressure. It can also help to assess whether or not thresholds in blood pressure exist below which the risk of complications is substantially reduced. Such thresholds would have substantial influence on the establishment of guidelines on clinical care.

People with type 2 diabetes have a greater incidence of cardiovascular disease, cerebrovascular disease, and renal disease than the general population. Epidemiological studies suggest that relative hyperglycaemia accounts for part but not all of the increased risk. $^{2-7}$ Raised blood pressure is more common in people with type 2 diabetes than in the general population, ${ }^{8-12}$ and in people without diabetes it is a major risk factor for myocardial infarction and stroke. ${ }^{13}{ }^{14}$ Epidemiological studies of the role of blood 
pressure on the development of cardiovascular disease have categorised people as either hypertensive or normotensive or have measured blood pressure on a single occasion, ${ }^{5615-17}$ whereas repeated measurements of blood pressure over several years should be more informative.

In these analyses, we evaluated the relation between systolic blood pressure over time and the development of macrovascular and microvascular complications using data from the UKPDS and looked for possible thresholds. We compared these results to those of the UKPDS trial of a policy of tight control of blood pressure. ${ }^{1}$ When the achieved reduction in risk notably exceeded that expected from observational data, analyses were performed to evaluate the presence of a treatment effect beyond that of blood pressure alone.

\section{Methods}

\section{Participants recruited to the UKPDS} diagnosed type 2 diabetes (defined as fasting plasma glucose concentrations over $6.0 \mathrm{mmol} / \mathrm{l}$ on two separate mornings) who were referred to the UKPDS and were aged 25 to 65 years. Recruitment occurred between 1977 and 1991 at 23 clinical centres in England, Scotland, and Northern Ireland. Exclusion criteria are presented elsewhere ${ }^{18}$; the main reasons were severe vascular disease, myocardial infarction or stroke within the year before recruitment, or major systemic illness.

\section{Participants in epidemiological analyses}

We studied the incidence of complications of diabetes in the 4801 white, Asian Indian, and Afro-Caribbean patients who had blood pressure measured at two and nine months after the diagnosis of diabetes. Of these, 3642 with complete data for potential confounders were evaluated in proportional hazards models. Their characteristics are presented in table 1.

\section{Participants in UKPDS blood pressure control study}

The UKPDS clinical trials of blood glucose and blood pressure control are described elsewhere. ${ }^{19} 20$ In summary, 1148 patients with hypertension, defined as previously receiving antihypertensive treatment and with a blood pressure $\geqslant 150 / 85 \mathrm{~mm} \mathrm{Hg}$ or not previously receiving antihypertensive treatment and a blood pressure $\geqslant 160 / 90 \mathrm{~mm} \mathrm{Hg}$, were randomised to a policy of tight control of blood pressure with a $\beta$ blocker or an angiotensin converting enzyme inhibitor or to a policy of less tight control. At entry, the mean duration of known diabetes was 2.6 years, and the patients were older and heavier than in the whole cohort (table 1). The aim in the group allocated to tight control was to achieve blood pressure values $<150 /<85 \mathrm{~mm} \mathrm{Hg}$. If this target was not met with maximal doses of a $\beta$ blocker or angiotensin converting enzyme inhibitor, additional agents were prescribed, including a loop diuretic, a calcium channel blocker, and a vasodilator. The aim in the group allocated to less tight control was to achieve blood pressure values $<180 /<105 \mathrm{~mm} \mathrm{Hg}$ without the use of a $\beta$ blocker or an angiotensin converting enzyme inhibitor but using the same stepwise addition of other treatments.
We enrolled 5102 of 7416 patients with newly

\section{Blood pressure measurement}

Blood pressure was measured with the person in a seated position after a five minute rest with a Copal UA-251 or a Takeda UA-751 electronic, auscultatory blood pressure reading machine (Andrew Stephens, Brighouse, West Yorkshire). The first reading was discarded, and the mean of the next three consecutive readings with a coefficient of variation below $15 \%$ was used. In participants with atrial fibrillation, examiners used a Hawksley random zero sphygmomanometer.

\section{Blood pressure exposure}

Blood pressure was measured firstly at baseline (mean of measures taken at two and nine months after diagnosis) and secondly as an updated mean of annual measurement of systolic blood pressure, calculated for each participant from baseline to each year of follow up. For example, at one year the updated mean is the average of the baseline and one year values and at three years it is the average of baseline, one year, two year, and three year values.

\section{Biochemical methods}

The biochemical methods used have been reported previously. ${ }^{21}$ Biochemical variables are quoted for measurements after the initial dietary run-in period.

\section{Clinical complications}

The clinical end points studied ${ }^{18}$ and their definitions ${ }^{19}$ were separated into aggregate and single end points (see box).

\section{Statistical analysis}

Incidence rates by category of systolic blood pressure The unadjusted incidence rates were calculated by dividing the number of people with a given complication by the person years of follow up for the given complication within each category of updated mean systolic blood pressure and reported as events per 1000 person years of follow up. The categories were defined (median values in parentheses) as: $<120(114)$, 120-129 (125), 130-139 (135), 140-149 (144), 150-159 (154), and $\geqslant 160$ (168) $\mathrm{mm} \mathrm{Hg}$ over the range of updated mean systolic blood pressures $85-230 \mathrm{~mm} \mathrm{Hg}$.

Table 1 Characteristics of patients included in proportional hazards models measured after three month dietary run-in after diagnosis of diabetes and those included in UKPDS blood pressure control study. ${ }^{1}$ Figures are means (SD) unless stated otherwise

\begin{tabular}{|c|c|c|}
\hline & $\begin{array}{l}\text { Proportional hazards model } \\
\text { of observational analyses } \\
\qquad(\mathrm{n}=3642)\end{array}$ & $\begin{array}{l}\text { Clinical trial of tight } v \text { less tight } \\
\text { blood pressure control policy } \\
(\mathrm{n}=1148)\end{array}$ \\
\hline Age (years) & $53(8)$ & $56(8)$ \\
\hline Proportion of men $(\%)$ & 60 & 55 \\
\hline $\begin{array}{l}\text { Ethnicity (\% white/Asian } \\
\text { Indian/Afro-Caribbean/other) }\end{array}$ & $82 / 10 / 8 / 0$ & $87 / 8 / 5 / 1$ \\
\hline Body mass index $\left(\mathrm{kg} / \mathrm{m}^{2}\right)$ & $27.7(5.3)$ & $29.6(19.2)$ \\
\hline Fasting plasma glucose $(\mathrm{mmol} / \mathrm{l})^{\star}$ & $7.9(6.6-10.0)$ & $7.4(6.2-9.5)$ \\
\hline Haemoglobin $\mathrm{A}_{1 \mathrm{c}}(\%)$ & $7.1(1.8)$ & $7.0(1.7)$ \\
\hline Systolic blood pressure $(\mathrm{mm} \mathrm{Hg})$ & $135(19)$ & $159(19)$ \\
\hline Low density lipoprotein cholesterol (mmol/l) & $3.5(1.0)$ & $3.6(1.1)$ \\
\hline High density lipoprotein cholesterol $(\mathrm{mmol} / \mathrm{l})$ & $1.06(0.24)$ & $1.10(0.27)$ \\
\hline Triglyceride $(\mathrm{mmol} / \mathrm{l}) \dagger$ & $1.5(0.9-2.5)$ & $1.6(0.9-2.7)$ \\
\hline Albuminuria $(\%) \ddagger$ & 13.3 & 17.7 \\
\hline
\end{tabular}

*Median (interquartile range)

†Geometric mean (1 SD range)

$\ddagger>50 \mathrm{mg} / \mathrm{l}$ in single morning sample.

University College London Medical School, Whittington Hospital, London N19 3UA John S Yudkin consultant physician

Oxford Centre for Diabetes,

Endocrinology and Metabolism, University of Oxford

David R Matthews consultant diabetologist

Selly Oak Hospital, Birmingham B29 6JD

Alex D Wright consultant physician

Diabetes Research Laboratories,

Oxford Centre for Diabetes,

Endocrinology and Metabolism,

University of

Oxford

Robert C Turner

director

Correspondence to: A Adler amanda.adler@dtu. ox.ac.uk

Professor Turner died unexpectedly after completing work on this paper 


\section{Aggregate end points}

- Complications related to diabetes (myocardial infarction, sudden death, angina, stroke, renal failure, lower extremity amputation or death from peripheral vascular disease, death from hyperglycaemia or hypoglycaemia, heart failure, vitreous haemorrhage, retinal photocoagulation, and cataract extraction)

- Death related to diabetes (myocardial infarction, sudden death, stroke, lower extremity amputation or fatal peripheral vascular disease, renal disease, hyperglycaemia or hypoglycaemia)

- All cause mortality

- Myocardial infarction (fatal myocardial infarction, non-fatal myocardial infarction, and sudden death)

- Stroke (fatal and non-fatal stroke)

- Lower extremity amputation or death from peripheral vascular disease

- Microvascular complications (retinopathy requiring photocoagulation, vitreous haemorrhage, and fatal or non-fatal renal failure)

\section{Single end points}

- Heart failure (non-fatal, without a precipitating myocardial infarction)

- Cataract extraction combined-that is, $<130 \mathrm{~mm} \mathrm{Hg}$ (median $120 \mathrm{~mm} \mathrm{Hg}$ ) -to increase the reliability of the results as there were few of these end points in this range. A separate model with updated mean systolic blood pressure as a continuous variable was used to determine risk reduction associated with a $10 \mathrm{~mm} \mathrm{Hg}$ reduction in blood pressure. (This is reflected in the regression line in figures 3 and 4.) The $95 \%$ confidence intervals were calculated on the basis of absolute floating risk. ${ }^{22} \mathrm{Log}$ linear relations are reported by convention. ${ }^{118}$ The risk reduction associated with a reduction of $10 \mathrm{~mm} \mathrm{Hg}$ in updated mean systolic blood pressure was calculated as 100\% minus the reciprocal of the hazard ratio expressed as a percentage.

The regression lines were fitted with updated mean systolic blood pressure as a continuous variable centred on the mean of the risk estimates for the categories 130-139 $\mathrm{mm} \mathrm{Hg}$ and 140-149 $\mathrm{mm} \mathrm{Hg}$. The $P$ value reported is that associated with systolic blood pressure as a continuous variable. Evaluation of a threshold level of systolic blood pressure for each complication was assessed by visual inspection. The risk reduction from the continuous variable model associated with a $10 \mathrm{~mm} \mathrm{Hg}$ reduction in observed systolic blood pressure was compared with the risk reduction seen in the UKPDS intervention trial of a tight versus a less tight policy of blood pressure control, for which no adjustment for potential confounders was required as they were balanced by the randomisation. ${ }^{1}$ The main exposure of interest for the observational analyses was updated mean systolic blood pressure regardless of the control policy or the antihypertensive treatments used.

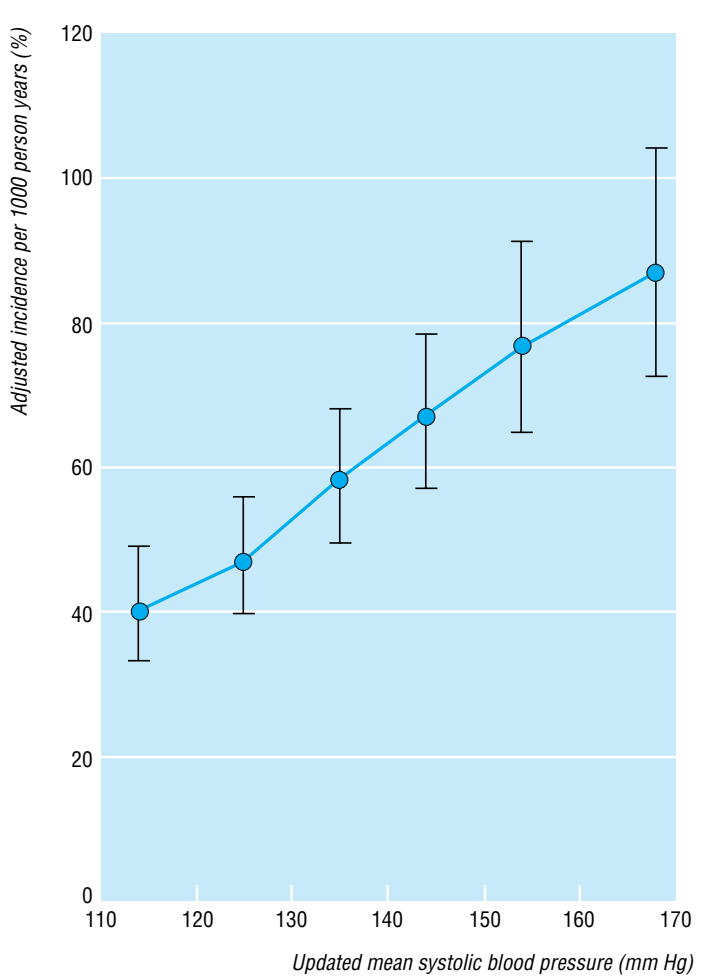

Fig 1 Incidence rate (95\% confidence interval) of any aggregate end point related to diabetes by category of updated mean systolic blood pressure, adjusted for age, sex, and ethnic group, expressed for white men aged 50-54 years at diagnosis and mean duration of diabetes of 10 years 


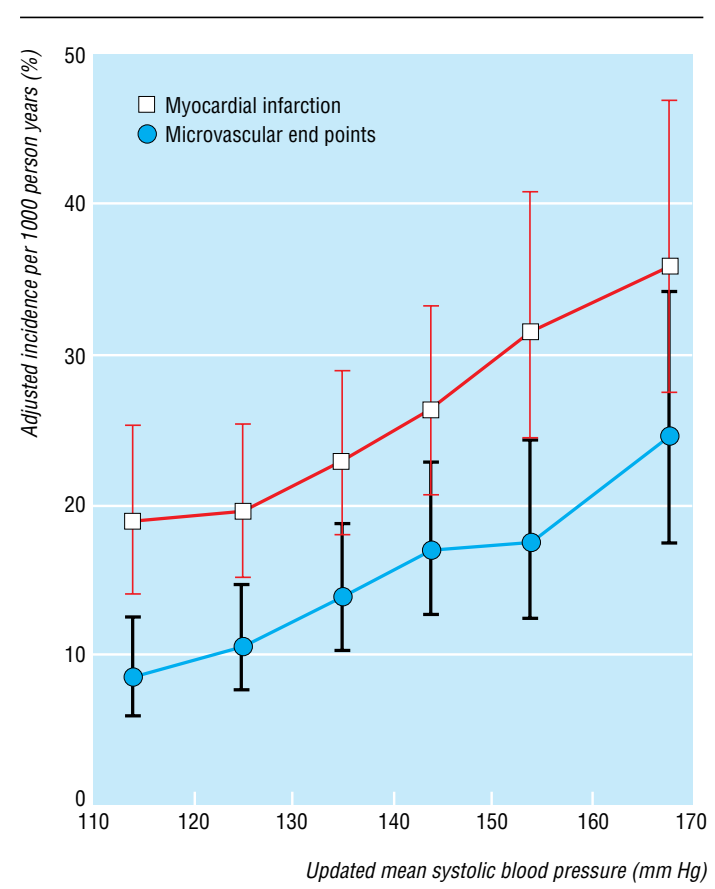

Fig 2 Incidence rates (95\% confidence interval) of myocardial infarction and microvascular end points by category of updated mean systolic blood pressure, adjusted for age, sex, and ethnic group expressed for white men aged 50-54 years at diagnosis and mean duration of diabetes of 10 years

To assess whether treatment with drugs to lower blood pressure reduced the complications independently of the reduction in blood pressure, a proportional hazards model was fitted that included allocation to tight versus less tight blood pressure policies, updated mean systolic blood pressure, age, sex, ethnic group, smoking, and concentrations of high and low density lipoprotein cholesterol, triglyceride, and albuminuria. An interaction term between blood pressure treatment and mean updated blood pressure was included.

Statistical analyses were performed with SAS version $6.12 .{ }^{23}$

\section{Results}

The risk of each of the macrovascular and microvascular complications of type 2 diabetes evaluated was strongly associated with blood pressure, as measured by updated mean systolic blood pressure. The incidence of cataract extraction was not associated with blood pressure. Figure 1 shows the incidence rated by category of updated mean systolic blood pressure for any end point related to diabetes adjusted for age, sex, ethnic group, and duration of diabetes. The increase in risk was monotonic, showing no evidence of a threshold, and showed a twofold increase over the range of systolic blood pressure from $<120 \mathrm{~mm} \mathrm{Hg}$ (median $114 \mathrm{~mm}$ $\mathrm{Hg}$ ) to $\geqslant 160 \mathrm{~mm} \mathrm{Hg}(168 \mathrm{~mm} \mathrm{Hg}$ ). The unadjusted and adjusted rates are shown in table 2. Figure 2 shows the adjusted incidence rates for myocardial infarction and microvascular end points, both being strongly associated to a similar degree with increasing blood pressure. Myocardial infarction, however, occurred about twice as frequently as microvascular end points at each level of blood pressure. Thus the incidence of myocardial infarc- tion increased from 18 per 1000 patient years in the group with the lowest systolic blood pressure to 33 per 1000 patient years in the group with blood pressure $>160 \mathrm{~mm} \mathrm{Hg}$, with the comparable data for microvascular disease being 7 to 21 per 1000 patient years.

The estimated hazard ratios associated with each category of updated mean systolic blood pressure, relative to the lowest category, are shown as log linear plots in figures 3 and 4 . Mortality related to diabetes and all cause mortality were both strongly associated with blood pressure $(\mathrm{P}<0.001)$. The risk of each of the complications evaluated, except cataract extraction, rose with increasing updated mean systolic blood pressure with and without adjustment for baseline variables including age, sex, ethnic group, lipid concentrations, $\mathrm{HbA}_{1 \mathrm{c}}$, smoking, and albuminuria. The decrease in risk for each $10 \mathrm{~mm} \mathrm{Hg}$ reduction of updated mean systolic blood pressure was between 12\% and 19\% for both macrovascular and microvascular complications (table 3 and figures 3 and 4 ).

There was no indication of a threshold for any of the complications examined below which risk no longer decreased nor a level above which risk no longer increased. The updated mean systolic blood pressure showed similar risk relations to baseline systolic blood pressure (table 3).

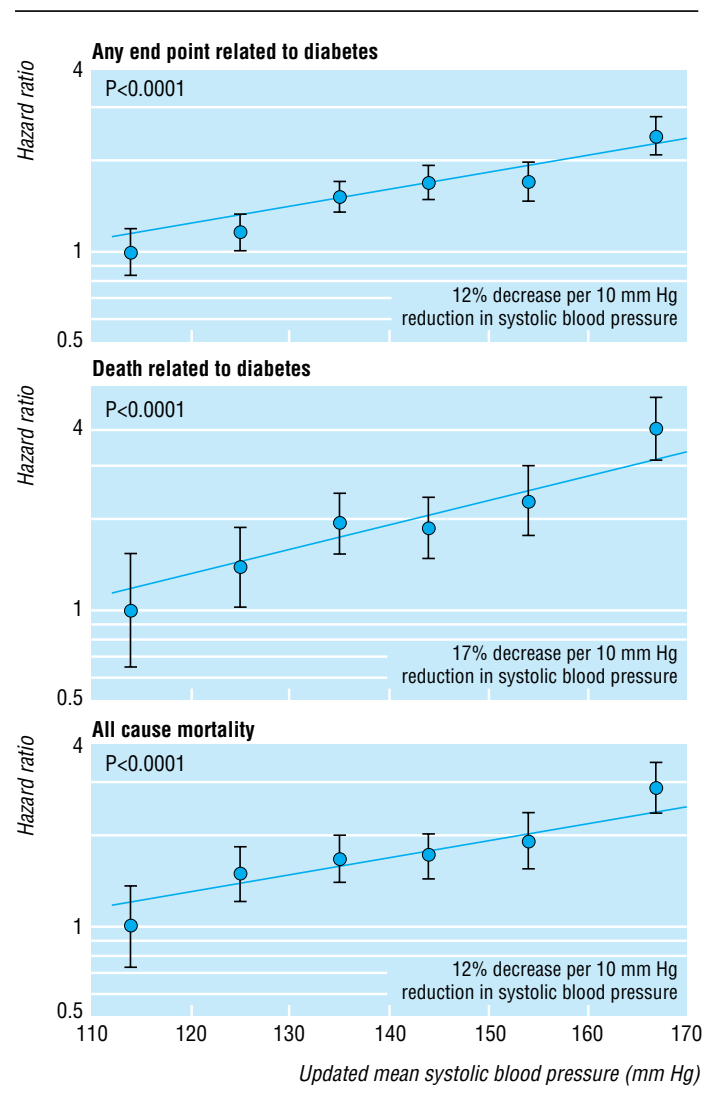

Fig 3 Hazard rates (95\% confidence intervals as floating absolute risks) as estimate of association between category of updated mean systolic blood pressure and any end point related to diabetes, death related to diabetes, and all cause mortality with log linear scales. Reference category (hazard ratio 1.0) is systolic blood pressure $<120$ $\mathrm{mm} \mathrm{Hg}$; P value reflects contribution of systolic blood pressure to multivariate model. Data adjusted for age at diagnosis, ethnic group, smoking status, presence of microalbuminuria, haemoglobin $\mathrm{A}_{1 \mathrm{c}}$, high and low density lipoprotein cholesterol, and triglyceride 
Table 2 Incidence of complications in patients with type 2 diabetes by category of updated mean systolic blood pressure. Rates per 1000 person years' follow up adjusted in Poisson regression model to white men aged 50 to 54 years at diagnosis and followed up for 7.5 to $<12.5$ years, termed "10 years" $(\mathrm{n}=4801)$

\begin{tabular}{|c|c|c|c|c|c|c|}
\hline & $<120 \mathrm{~mm} \mathrm{Hg}$ & $120-129 \mathrm{~mm} \mathrm{Hg}$ & $130-139 \mathrm{~mm} \mathrm{Hg}$ & $140-149 \mathrm{~mm} \mathrm{Hg}$ & $150-159 \mathrm{~mm} \mathrm{Hg}$ & $\geqslant 160 \mathrm{~mm} \mathrm{Hg}$ \\
\hline \multicolumn{7}{|l|}{ Aggregate end points } \\
\hline \multicolumn{7}{|c|}{ Complications related to diabetes: } \\
\hline Events/person years & $198 / 8662$ & $366 / 9327$ & $375 / 9946$ & $365 / 8044$ & $272 / 5107$ & $262 / 4493$ \\
\hline Unadjusted rate & 22.9 & 28.5 & 37.7 & 45.4 & 53.3 & 58.3 \\
\hline Adjusted rate $(95 \% \mathrm{Cl})$ & $36.0(29.7$ to 43.6$)$ & 40.4 (34.0 to 47.9$)$ & 51.3 (43.9 to 60.0$)$ & 58.3 (49.7 to 68.3$)$ & 67.1 (56.4 to 79.8$)$ & 76.2 (63.6 to 91.3 ) \\
\hline \multicolumn{7}{|l|}{ Deaths related to diabetes: } \\
\hline Events/person years & $40 / 9353$ & $59 / 10406$ & $115 / 11540$ & $104 / 9589$ & $96 / 6207$ & $110 / 5537$ \\
\hline Unadjusted rate & 4.3 & 5.7 & 10.0 & 10.8 & 15.5 & 19.9 \\
\hline Adjusted rate $(95 \% \mathrm{Cl})$ & $9.6(6.5$ to 14.1$)$ & $10.0(7.2$ to 13.9$)$ & 15.7 (11.9 to 20.7) & 15.4 (11.6 to 20.5$)$ & 21.3 (15.9 to 28.7$)$ & 28.7 (21.3 to 38.7$)$ \\
\hline \multicolumn{7}{|l|}{ All cause mortality: } \\
\hline Events/person years & $65 / 9353$ & $133 / 10406$ & $183 / 11540$ & $184 / 9589$ & $152 / 6207$ & $163 / 5537$ \\
\hline Unadjusted rate & 6.9 & 12.8 & 15.9 & 19.2 & 24.5 & 29.4 \\
\hline Adjusted rate $(95 \% \mathrm{Cl})$ & $14.4(10.7$ to 19.5$)$ & 20.3 (16.0 to 25.8$)$ & $22.2(17.8$ to 27.7$)$ & 23.8 (19.1 to 29.7$)$ & 29.1 (23.0 to 36.9) & $36.2(28.4$ to 46.1$)$ \\
\hline \multicolumn{7}{|c|}{ Fatal or non-fatal myocardial infarction: } \\
\hline Events/person years & $85 / 9083$ & $104 / 10064$ & $152 / 11048$ & $149 / 9198$ & $114 / 5912$ & $115 / 5326$ \\
\hline Unadjusted rate & 9.4 & 10.3 & 13.8 & 16.2 & 19.3 & 21.6 \\
\hline Adjusted rate $(95 \% \mathrm{Cl})$ & 18.4 (13.8 to 24.6$)$ & $17.6(13.5$ to 22.9$)$ & $21.9(17.3$ to 27.8$)$ & $24.2(19.1$ to 30.7$)$ & 28.7 (22.2 to 37.3$)$ & 33.1 (25.3 to 43.3$)$ \\
\hline \multicolumn{7}{|l|}{ Stroke: } \\
\hline Events/person years* & & $36 / 19523$ & $41 / 11334$ & $56 / 9359$ & $50 / 6008$ & $58 / 5271$ \\
\hline Unadjusted rate & & 1.8 & 3.6 & 6.0 & 8.3 & 11.0 \\
\hline Adjusted rate $(95 \% \mathrm{Cl})$ & & $2.8(1.7$ to 4.4$)$ & $4.4(2.8$ to 6.9$)$ & 6.5 (4.3 to 9.9) & 8.7 (5.6 to 13.5$)$ & 11.9 (7.6 to 18.6$)$ \\
\hline \multicolumn{7}{|c|}{ Lower extremity amputation or death from peripheral vascular disease: } \\
\hline Events/person years* & & $11 / 19573$ & $17 / 11393$ & $13 / 9432$ & $11 / 6081$ & $15 / 5409$ \\
\hline Unadjusted rate & & 0.6 & 1.5 & 1.4 & 1.8 & 2.8 \\
\hline Adjusted rate $(95 \% \mathrm{Cl})$ & & $1.0(0.4$ to 2.4$)$ & $2.4(1.1$ to 5.2$)$ & $2.1(0.9$ to 4.8$)$ & $2.8(1.2$ to 6.6$)$ & $4.8(2.1$ to 11.1$)$ \\
\hline \multicolumn{7}{|c|}{ Fatal or non-fatal microvascular disease: } \\
\hline Events/person years & $52 / 9150$ & $72 / 10059$ & $102 / 10971$ & $100 / 9026$ & $67 / 5769$ & $74 / 5084$ \\
\hline Unadjusted rate & 5.7 & 7.2 & 9.3 & 11.1 & 11.6 & 14.6 \\
\hline Adjusted rate $(95 \% \mathrm{Cl})$ & 7.3 (5.0 to 10.6$)$ & $8.9(6.4$ to 12.4$)$ & 11.9 (8.8 to 16.1$)$ & $14.2(10.5$ to 19.3$)$ & 15.2 (10.8 to 21.4$)$ & 20.8 (14.8 to 29.2) \\
\hline \multicolumn{7}{|l|}{ Single end point } \\
\hline \multicolumn{7}{|l|}{ Heart failure: } \\
\hline Events/person years & & 26/19 534 & $34 / 11326$ & $33 / 9356$ & $31 / 6036$ & $34 / 5331$ \\
\hline Unadjusted rate* & & 1.3 & 3.0 & 3.5 & 5.1 & 6.4 \\
\hline Adjusted rate $(95 \% \mathrm{Cl})$ & & 2.4 (1.4 to 4.2$)$ & 4.2 (2.5 to 6.9$)$ & 4.1 (2.5 to 6.9$)$ & 5.6 (3.3 to 9.6$)$ & $7.0(4.0$ to 12.0$)$ \\
\hline \multicolumn{7}{|l|}{ Cataract extraction: } \\
\hline Events/person years & $37 / 9173$ & $53 / 10136$ & $55 / 11113$ & $62 / 9190$ & $37 / 5993$ & $35 / 5296$ \\
\hline Unadjusted rate & 4.0 & 5.2 & 4.9 & 6.7 & 6.2 & 6.6 \\
\hline Adjusted rate $(95 \% \mathrm{Cl})$ & 4.7 (3.0 to 7.5$)$ & 5.1 (3.4 to 7.7$)$ & 4.4 (2.9 to 6.6$)$ & 5.2 (3.5 to 7.8$)$ & $4.4(2.8$ to 7.0$)$ & 4.4 (2.7 to 7.2$)$ \\
\hline
\end{tabular}

Table 3 also shows the risk reductions associated with a $10 \mathrm{~mm} \mathrm{Hg}$ reduction in blood pressure in the observational analysis compared with the risk reduction associated with a $10 \mathrm{~mm} \mathrm{Hg}$ median difference in blood pressure from the clinical trial of blood pressure control. ${ }^{1}$ After exclusion of cataract extractions, the relation with blood pressure tended to be stronger in the clinical trial than in the observational analysis, although in the clinical trial the confidence intervals were wider (table 3 ), reflecting the smaller number of people at risk and of events. ${ }^{1}$ With adjustment for updated mean systolic blood pressure in the trial, allocation to tight blood pressure control had a greater effect on reducing the risk of heart failure $(\mathrm{P}=0.0054$; 17 events in 749 patients allocated to tight control and 20 events in 384 patients allocated to less tight control) than expected from the blood pressure reduction per se. This was also true for stroke $(\mathrm{P}=0.027)$, with 29 events in 752 patients allocated to tight control and 26 events in 386 patients allocated to less tight control, and for all deaths related to diabetes $(\mathrm{P}=0.038)$, with 63 events in 752 patients allocated to tight control and 49 events in 386 patients allocated to less tight control.
There was no interaction between treatment and updated mean blood pressure.

\section{Discussion}

This observational analysis shows an important association between the occurrence of each of the diabetic complications evaluated (except cataract extraction), including all cause mortality, and systolic blood pressure exposure across the range observed in patients with type 2 diabetes. This association persisted after adjustment for other characteristics that are associated with risk of complications (age, sex, ethnic group, glycaemia, lipid concentrations, smoking, and albuminuria). On average, each $10 \mathrm{~mm} \mathrm{Hg}$ reduction in systolic blood pressure was associated with a $12 \%$ decrease in the risk of any end point related to diabetes and a $15 \%$ reduction in the risk of death related to diabetes. Myocardial infarction occurred more commonly than microvascular complications, but the relative risk reduction for a $10 \mathrm{~mm} \mathrm{Hg}$ reduction in systolic blood pressure was similar at $11 \%$ and $13 \%$, respectively. 
This observational analysis provides an estimate of the reduction in risk that might be achieved by the therapeutic lowering of blood pressure. While it is important to realise that epidemiological associations cannot necessarily be transferred to clinical practice, the results are consistent with those achieved by the policy of tight control of blood pressure in the clinical trial. ${ }^{1}$ Whereas tight control did not significantly reduce the risk of myocardial infarction in the clinical trial, the effect size was commensurate with the observational analysis. The risk reductions in the clinical trial of tight control seemed to be greater than those anticipated from the epidemiological analyses for any complications or deaths related to diabetes, stroke, microvascular disease, and heart failure. ${ }^{1}$ After allowance for differences in blood pressure between the tight and less tight policies in the clinical trial, this apparent treatment effect, per se, was significant only for deaths related to diabetes, stroke, and heart failure. The absence of significant interaction suggests that treatment effect does not differ by level of blood pressure. The heart outcomes prevention evaluation studies (HOPE and MICRO-HOPE) that used ramipril can also be interpreted to have effects beyond those anticipated by changes in blood pressure alone. ${ }^{24}{ }^{25}$ This suggests the possibility that treatment with angiotensin converting enzyme inhibitors ${ }^{26}{ }^{27}$ and $\beta$ block$\mathrm{ers}^{28}{ }^{29}$ may have cardioprotective effects separate from blood pressure reduction. For example, both are beneficial in heart failure. ${ }^{18}{ }^{30}{ }^{31}$ The diminished risk of heart failure may have reduced the risk of embolic stroke, but no direct data are available. Effects greater than anticipated have also been shown in studies in the general population, where the risk reduction in odds of stroke from pooled trials of antihypertensive drug treatment exceeded the $35-40 \%$ expected from epidemiological studies. ${ }^{32}$ It is possible that the association between blood pressure and cardiovascular disease differs in magnitude in diabetic and non-diabetic populations, which could not be tested in this study. In support of this possibility, the multiple risk factor intervention trial (MRFIT) observed that the association of
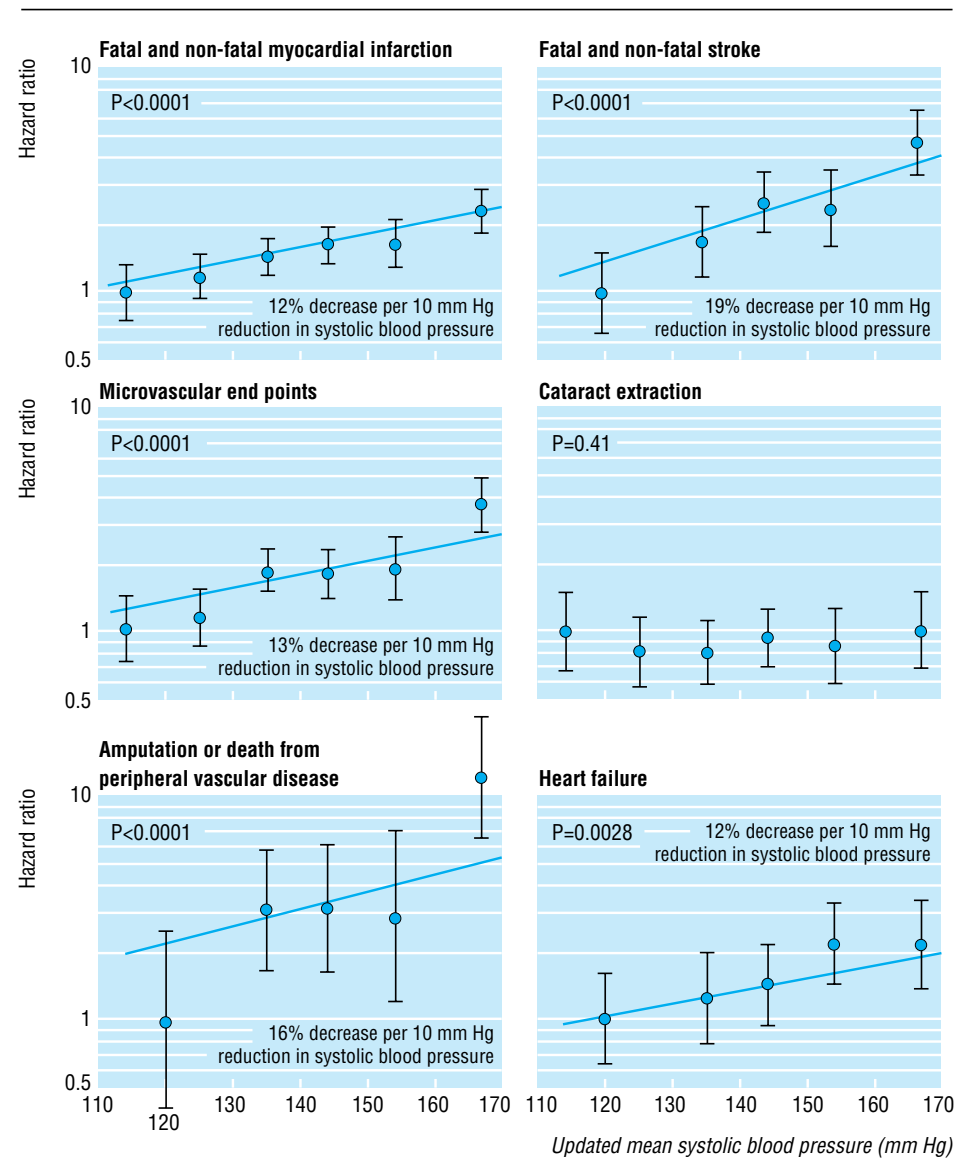

Fig 4 Hazard rates (95\% confidence intervals as floating absolute risks) as estimate of association between category of updated mean systolic blood pressure and myocardial infarction, stroke, microvascular end points, cataract extraction, lower extremity amputation, or fatal peripheral vascular disease and heart failure, with log linear scales. Reference category (hazard ratio 1.0) is systolic blood pressure $<120 \mathrm{~mm} \mathrm{Hg}$ for myocardial infarction, microvascular disease, and cataract extraction and $<130 \mathrm{~mm} \mathrm{Hg}$ for stroke, lower extremity amputation or fatal peripheral vascular disease, and heart failure; $\mathrm{P}$ value reflects contribution of systolic blood pressure to multivariate model. Data adjusted for age at diagnosis of diabetes, ethnic group, smoking status, presence of albuminuria, haemoglobin $A_{10}$, high and low density lipoprotein cholesterol, and triglyceride

Table 3 Observational data analysis of relation between systolic blood pressure exposure and complications of diabetes as estimated by risk reduction for $10 \mathrm{~mm} \mathrm{Hg}$ reduction in systolic blood pressure, measured at baseline and as updated mean, controlled for age at diagnosis of diabetes, sex, ethnic group, smoking, microalbuminuria, haemoglogin $A_{1 c}$ concentration, high and low density lipoprotein cholesterol, and triglycerides $(n=3642)$ compared with results of clinical trial of tight $v$ less tight blood pressure control policy $(\mathrm{n}=1148)^{1}$

\begin{tabular}{|c|c|c|c|c|c|c|c|c|}
\hline & \multirow[b]{3}{*}{$\begin{array}{l}\text { No of } \\
\text { events }\end{array}$} & \multicolumn{4}{|c|}{ Observational analyses } & \multicolumn{3}{|c|}{ Clinical trial (less tight $v$ tight policy) $)^{1}$} \\
\hline & & \multicolumn{2}{|l|}{ Baseline SBP } & \multicolumn{2}{|c|}{ Updated mean SBP } & \multirow[b]{2}{*}{$\begin{array}{l}\text { No of } \\
\text { events }\end{array}$} & \multirow[b]{2}{*}{$\begin{array}{c}\text { Decrease in risk (\%)/10 mm Hg } \\
\text { difference in SBP (95\% CI) }\end{array}$} & \multirow[b]{2}{*}{$P$ value } \\
\hline & & $\begin{array}{c}\text { Decrease in risk } \\
(\%) / 10 \mathrm{~mm} \mathrm{Hg} \text { reduction } \\
(95 \% \mathrm{Cl})\end{array}$ & $P$ value & $\begin{array}{c}\text { Decrease in risk } \\
(\%) / 10 \mathrm{~mm} \mathrm{Hg} \text { reduction } \\
(95 \% \mathrm{Cl})\end{array}$ & $P$ value & & & \\
\hline \multicolumn{9}{|l|}{ Aggregate end points } \\
\hline Any end point related to diabetes & 1255 & $9(7$ to 12$)$ & $<0.0001$ & 12 (9 to 14$)$ & $<0.0001$ & 429 & 24 (8 to 38 ) & 0.0046 \\
\hline Deaths related to diabetes & 346 & 19 (15 to 23$)$ & $<0.0001$ & 17 (13 to 21$)$ & $<0.0001$ & 144 & 32 (6 to 51$)$ & 0.0019 \\
\hline All cause mortality & 597 & $13(10$ to 17$)$ & $<0.0001$ & 12 (9 to 16$)$ & $<0.0001$ & 217 & $18(-8$ to 37$)$ & $>0.05$ \\
\hline Myocardial infarction & 496 & $13(9$ to 16$)$ & $<0.0001$ & $12(7$ to 16$)$ & $<0.0001$ & 176 & $21(-7$ to 41$)$ & $>0.05$ \\
\hline Stroke & 162 & $13(7$ to 19$)$ & 0.0002 & 19 (14 to 24$)$ & $<0.0001$ & 72 & 44 (11 to 65$)$ & 0.013 \\
\hline Peripheral vascular disease ${ }^{*}$ & 41 & 30 (20 to 39$)$ & $<0.0001$ & 16 (9 to 23 ) & $<0.0001$ & 16 & $49(-37$ to 81$)$ & $>0.05$ \\
\hline Microvascular disease & 323 & 10 (4 to 15$)$ & 0.0007 & 13 (9 to 26 ) & $<0.0001$ & 122 & 37 (11 to 56$)$ & 0.0092 \\
\hline \multicolumn{9}{|l|}{ Single end points } \\
\hline Heart failure & 104 & 14 (5 to 21$)$ & 0.0016 & 15 (4 to 19$)$ & $<0.0001$ & 45 & 56 (6 to 80$)$ & 0.0043 \\
\hline Cataract extraction & 195 & $7(0$ to 14$)$ & 0.043 & $-3(-11$ to 5$)$ & 0.41 & 42 & $-34(40$ to -202$)$ & $>0.05$ \\
\hline
\end{tabular}

$\mathrm{SBP}=$ systolic blood pressure.

*Lower extremity amputation or fatal peripheral vascular disease. 
systolic blood pressure and death from cardiovascular disease was of a lower magnitude in diabetic compared with non-diabetic men. ${ }^{15}$ Stroke and heart failure were the complications least strongly associated with glycaemia, ${ }^{2}$ suggesting that for these complications, by comparison, raised blood pressure is of greater pathogenetic importance.

\section{Lack of thresholds}

We observed no thresholds of systolic blood pressure for any complication of diabetes. This suggests that there is no specific target blood pressure to aim for but that the nearer to normal systolic blood pressure the lower the risk of complications, in accord with recommendations to reduce systolic blood pressure to less than $130 \mathrm{~mm}$ $\mathrm{Hg}^{33-35}$ or less than $125 \mathrm{~mm} \mathrm{Hg}$ in the presence of microalbuminuria. ${ }^{36}$ Whether these target values can realistically be achieved depends on an individual's initial blood pressure and willingness to modify life style or to take several drugs that may have side effects. Neither our study nor the hypertension optimal treatment (HOT) study ${ }^{37}$ found a J or $\mathrm{U}$ shaped association between systolic blood pressure and complications, which is now thought to reflect coexisting morbidity with low blood pressures rather than the effect of treatment. ${ }^{38}$ Unlike the HOT study the UKPDS did not observe a flattening of the relation at low levels of blood pressure. There was no indication of a level above which systolic blood pressure was no longer associated with an increased risk of complications. Thus any reduction of raised blood pressure is likely to have benefit.

As in this analysis, a large study of diabetic applicants for life insurance in the United States showed that hypertension was strongly associated with all cause mortality. ${ }^{39}$ Our finding of a $15 \%$ risk reduction for deaths related to diabetes associated with $10 \mathrm{~mm} \mathrm{Hg}$ systolic change is similar to the $15 \%$ risk reduction observed for cardiovascular death in a global study ${ }^{40}$ and to that calculated from the data in the multiple risk factor intervention trial (MRFIT) $)^{15}$ in people with diabetes. Other studies have observed an association between blood pressure and cardiovascular mortality. ${ }^{149}{ }^{41-42}$ The increasing risk of stroke with raised systolic blood pressure has also been shown. ${ }^{43-45}$

These observational analyses show that people at high risk for diabetic complications can be identified on the basis of as few as two blood pressure readings within the year after diagnosis as these measurements were associated with a risk of complications of similar magnitude to the updated mean systolic blood pressure measured over many years. Regression dilution bias from the baseline measurement was probably minimised as two readings taken six months apart, rather than a single measurement, were used in the model. The similarity of the risk probably reflects tracking of blood pressure in populations over years. ${ }^{46}$ The choice of systolic rather than diastolic pressure reflects convention and the knowledge that both are associated with heart disease. ${ }^{32} 4047$

This analysis indicates the importance of early assessment of blood pressure in the course of diabetes. Improved control of blood pressure in diabetic patients has been shown to be effective in reducing the risk of cardiovascular complications $^{3748}$ and nephropathy, ${ }^{50}$ as well as providing considerable savings in healthcare costs. $^{51}{ }^{52}$ Whereas treatment of glycaemia in patients

\section{What is already known on this topic}

People with diabetes who also have hypertension are more likely to develop complications

Treatment of blood pressure in these individuals reduces the risk of complications

\section{What this study adds}

There is a direct relation between the risk of complications of diabetes and systolic blood pressure over time

No threshold of systolic blood pressure was observed for a substantive change in risk for any of the clinical outcomes examined

The lower the systolic blood pressure the lower the risk of complications

There may be additional risk reduction with angiotensin converting enzyme inhibitors and $\beta$ blockers over and above that associated with lowering of blood pressure

with type 2 diabetes is difficult because of the progressive hyperglycaemia, ${ }^{53}$ it is easier to maintain improved blood pressure control, although with time additional blood pressure lowering agents are required. ${ }^{1}$ As the risk of diabetic complications rises across the range of blood pressures studied, lifestyle interventions that also reduce blood pressure in people without hypertension ${ }^{54}$ or not at high risk for diabetes ${ }^{55}$ should also be beneficial in diabetic patients. Targeting and treating patients with the highest blood pressure will reduce individual risk the most, but targeting and treating people with moderately raised blood pressure will reduce the risk in greater numbers of people. ${ }^{56}$ The UKPDS provides an evidence base for the management of raised blood pressure and hyperglycaemia to reduce the complications of type 2 diabetes.

The cooperation of the patients and many NHS and non-NHS staff at the centres is much appreciated. Details of participating centres can be found on the $B M F$ s website.

Contributors: AIA coordinated the writing of the paper and participated in interpretation of results. IMS selected the methodology, carried out the statistical analyses, and participated in interpretation and revision of the paper. HAWN, JSY, DRM, and ADW participated in interpretation and revision of the paper. CAC participated in the preparation of the data and interpretation and revision of the paper. RCT and RRH were the principal investigators, planned and designed the study, and participated in interpretation and revision of the paper. RCT was also responsible for the initial draft of the paper. RRH is guarantor.

Funding: The major grants for this study were from the UK Medical Research Council, British Diabetic Association, the UK Department of Health, The National Eye Institute and The National Institute of Digestive, Diabetes and Kidney Disease in the National Institutes of Health, United States, The British Heart Foundation, Novo Nordisk, Bayer, Bristol-Myers Squibb, Hoechst, Lilly, Lipha, and Farmitalia Carlo Erba. Details of other funding companies and agencies, the supervising committees, and all participating staff can be found on the $B M$ s s website.

Competing interests: AIA has received fees for speaking from Bristol-Myers Squibb, SmithKline Beecham, and Pfizer. IMS has received support for attending conferences from Zeneca and Hoechst and fees for speaking from Hoechst. CAC has received support for attending conferences from Bristol-Myers Squibb, Novo Nordisk, and Pfizer and fees for speaking from 
Bristol-Myers Squibb and Novo Nordisk.JSY has received consultancy fees from SmithKline Beecham. DRM has received fees for speaking from Bristol-Myers Squibb, Novo Nordisk, SmithKline Beecham, and Lilly and research funding from Lilly. RRH has received fees for consulting from Baver, Boehringer Mannheim, Bristol-Myers Squibb, Hoechst, Lilly, Novo Nordisk, Pfizer, and SmithKline Beecham; support for attending conferences from Bayer, Bristol-Myers Squibb, Hoechst, Lilly, Lipha, Novo Nordisk, and SmithKline Beecham; and research funding from Bayer, Bristol-Myers Squibb, Lilly, Lipha, and Novo Nordisk.

1 UKPDS Group. Tight blood pressure control and risk of macrovascular and microvascular complications in type 2 diabetes (UKPDS 38). BMJ 1998;317:703-13.

2 Stratton IM, Adler AI, Neil HAW, Matthews DR, Manley SE, Cull CA, et al. Epidemiological association of glycaemia with macrovascular and microvascular complications of type 2 diabetes (UKPDS 35). BMJ 2000; 321:405-12.

3 Klein R. Hyperglycemia and microvascular and macrovascular disease in diabetes. Diabetes Care 1995;18:258-68.

4 Standl E, Balletshofer B, Dahl B, Weichenhain B, Stiegler, Hormann A, et al. Predictors of 10-year macrovascular and overall mortality in patients with NIDDM: the Munich general practitioner project. Diabetologia 1996:39:1540-5.

5 Hanefeld M, Fischer S, Julius U, Schulze J, Schwanebeck U, Schmechel H, et al. Risk factors for myocardial infarction and death in newly detected NIDDM: the diabetes intervention study, 11-year follow-up. Diabetologia 1996;39:1577-83.

6 Lehto S, Ronnemaa T, Haffner SM, Pyörälä K, Kallio V, Laakso M. Dyslipidemia and hyperglycemia predict coronary heart disease events in middle-aged patients with NIDDM. Diabetes 1997;46:1354-9.

7 Wei M, Gaskill SP, Haffner SM, Stern MP. Effects of diabetes and level of glycaemia on all-cause and cardiovascular mortality. Diabetes Care 1998;21:1167-72.

Kannel W, McGee D. Diabetes and cardiovascular disease. The Framingham study. JAMA 1979;241:2035-8.

9 Cowie CC, Harris MI. Physical and metabolic characteristics of person with diabetes. In: Harris MI, Cowie CC, Stern MP, Boyko EJ, Reiber GE Bennett PH, eds. Diabetes in America. 2nd ed. Washington, DC: National Institutes of Health, National Institute of Diabetes and Digestive and Kidney Diseases, 1995.

10 Manson JAE, Colditz GA, Stampfer MJ, Willett WC, Krolewski AS, Rosner B, et al. A prospective study of maturity-onset diabetes mellitu and risk of coronary heart disease and stroke in women. Arch Intern Med 1991;151:1141-7.

11 Barrett-Connor EL, Cohn BA, Wingard DL, Edelstein SL. Why is diabetes mellitus a stronger risk factor for fatal ischemic heart disease in women than in men? JAMA 1991;265:627-31.

12 Hypertension in Diabetes Study Group. HDS I: prevalence of hypertension in newly presenting type 2 diabetic patients and the association with risk factors for cardio-vascular and diabetic complications. J Hypertens 1993;11:309-17.

13 Keil JE, Sutherland SE, Knapp RG, Lackland DT, Gazes PG, Tyroler HA Mortality rates and risk factors for coronary disease in black as compared with white men and women. NEngl J Med 1993:329:73-8.

14 Collins R, Peto R, MacMahon S, Herbert P, Fiebach N, Eberlein K, et al. Blood pressure, stroke, and coronary heart disease. Lancet 1990;335:82738 .

15 Stamler J, Vaccaro O, Neaton JD, Wentworth D. Diabetes, other risk factors, and 12 year cardiovascular mortality for men screened in the multiple risk factor intervention trial. Diabetes Care 1993;16:434-44.

16 Kuusisto J, Mykkänen L, Pyörälä K, Laakso M. NIDDM and its metabolic control predict coronary heart disease in elderly subjects. Diabetes 1994:43:960-7.

17 Uusitupa MI, Niskanen LK, Siitonen O, Voutilainen E, Pyörälä K Ten-year cardiovascular mortality in relation to risk factors and abnormalities in lipoprotein composition in type 2 (non-insulindependent) diabetic and non-diabetic subjects. Diabetologia 1993;36:1175-84.

18 UKPDS Group. Intensive blood glucose control with sulphonylureas or insulin compared with conventional treatment and risk of complication in patients with type 2 diabetes (UKPDS 33). Lancet 1998;352:837-53.

19 UKPDS Group. UK prospective diabetes study VIII: study design, progress and performance. Diabetologia 1991;34:877-90.

20 Hypertension in Diabetes Study Group. HDS III: prospective study of therapy in type 2 diabetic patients - efficacy of ACE inhibitor and blocker. Diabetic Med 1994;11:773-89.

21 UKPDS Group. UK prospective diabetes study XI: biochemical risk factors in type 2 diabetic patients at diagnosis compared with age-matched normal subjects. Diabetic Med 1994;11:534-44

22 Easton DF, Peto J, Babiker AG. Floating absolute risk: an alternative to relative risk in survival and case-control analysis avoiding an arbitrary reference group. Stat Med 1991;10:1025-35.

23 SAS. Version 6. Cary, NC: SAS Institute, 1990.

24 Heart Outcome Prevention Evaluation Study Investigators. Effect of an angiotensin-converting enzyme inhibitor, ramipril, on death from cardiovascular causes, myocardial infarction and stroke in high-risk patients. N Engl J Med 2000;342:145-60.

25 Heart Outcomes Prevention Evaluation Study Investigators. Effects of ramipril on cardiovascular and microvascular outcomes in people with diabetes mellitus: results of the HOPE study and MICRO-HOPE substudy. Lancet 2000;355:253-9.

26 Borghi C, Ambrosioni E. Evidence-based medicine and ACE inhibition. J Cardiovasc Pharmacol 1998;32(suppl 2):24-35.
27 Ferrari R. Effect of ACE inhibition on myocardial ischaemia. Eur Heart $J$ 1998;19(suppl J):30-5

28 Doughty RN, Rodgers A, Sharpe N, MacMahon S. Effects of beta-blocker therapy on mortality in patients with heart failure: a systematic overview of randomised controlled trails. Eur Heart J 1997; 18:560-5

29 Freemantle N, Cleland J, Young P, Mason J, Harrison J. $\beta$ Blockade after myocardial infarction: systematic review and meta-regression analysis. BMJ 1999;318:1730-7

30 Psaty BM, Smith NL, Siscovick DS, Koepsell TD, Weiss NS, Heckbert SR, et al. Health outcomes associated with antihypertensive therapies used as first-lines agents. JAMA 1997;277:739-45.

31 UKPDS Group. Efficacy of atenolol and captopril in reducing risk of macrovascular and microvascular complications in type 2 diabetes (UKPDS 39). BMJ 1998;317:713-20.

32 MacMahon S, Peto R, Cutler J, Collins R, Sorlie P, Neaton J, et al. Blood pressure, stroke, and coronary heart disease. Part 1: prolonged differences in blood pressure: prospective observational studies corrected for the regression dilution bias. Lancet 1990;335:765-74

33 Joint National Committee on Prevention, Detection, Evaluation and Treatment of High Blood Pressure. Sixth report. Arch Intern Med 1997:157:2413-46

34 Meltzer S, Leiter L, Daneman D, Gerstein HC, Lau D, Ludwig S, et al. 1998 clinical practice guidelines for the management of diabetes in Canada. Can Med Assoc J 1998;159(suppl 8):1-29.

35 American Diabetes Association. Standards of medical care for patients with diabetes mellitus. Diabetes Care 1998;21(suppl 1):23-31.

36 British Cardiac Society, British Hyperlipidaemia Association, British Hypertension Society, British Diabetic Association. Joint British recommendations on prevention of coronary heart disease in clinical practice. Heart 1998;80(suppl 2):1-29.

37 Hansson L, Zanchetti A, Carruthers SG, Dahlöf B, Elmfeldt D, Julius S, et al. Effect of intensive blood-pressure lowering and low-dose aspirin in patients with hypertension: principal results of the hypertension optimal treatment (HOT) randomised trial. Lancet 1998;351:1755-62.

38 Vatten LJ, Holmen J, Kruger O, Forsen L, Tverdal A. Low blood pressure and mortality in the elderly: a 6-year follow-up of 18,022 Norwegian men and women age 65 years and older. Epidemiology 1995;6:70-3.

39 Goodkin G. Mortality in diabetes. A 20 year mortality study. J Occup Med $1975 ; 17: 716-21$

40 Van den Hoogen PCW, Feskens EJM, Nagelkerke NJD, Menotti A, Nissinen A, Kromhout D. The relation between blood pressure and mortality due to coronary heart disease among men in different parts of the world. N Engl J Med 2000;342:1-8.

41 Rosengren A, Welin L, Tsipogianni A, Wilhelmsen L. Impact of cardiovascular risk factors on coronary heart disease among middle aged diabetic men: a general population study. BMJ 1989;299:1127-31.

42 Bruno G, Merletti F, Boffetta P, Cavallo-Perin P, Bargero G, Gallone G, et al. Impact of glycaemic control, hypertension and insulin treatment on general and cause-specific mortality: an Italian population-based cohor of type II (non-insulin-dependent) diabetes mellitus. Diabetologia 1999;42:297-301.

43 Lehto S, Ronnemaa T, Pyörälä K, Laakso M. Predictors of stroke in middle-aged patients with non-insulin-dependent diabetes. Stroke 1996;27:63-8.

44 Barrett-Connor E, Khaw K-T. Diabetes mellitus: an independent risk factor for stroke? Am J Epidemiol 1988;128:116-23.

45 Palumbo PJ, Elveback LR, Whisnant JP. Neurological complications of diabetes mellitus: transient ischemic attack, stroke, and periphera neuropathy. Adv Neurol 1978;19:593-601.

46 Tate RB, Manfreda J, Krahn AD, Cuddy TE. Tracking of blood pressure over a 40-year period in the University of Manitoba follow-up study, 1948-1988. Am J Epidemiol 1995;142:946-54.

47 Cutler JA. High blood pressure and end-organ damage. J Hypertens Supp 1996;14:3-6

48 Tuomilehto J, Rastenyte D, Birkenhäger WH, Thijs L, Antikainen R, Bulpitt CJ, et al. Effect of calcium-channel blockade in older patients with diabetes and systolic hypertension. N Engl J Med 1999;320:677-84.

49 Curb JD, Pressel SL, Cutler JA, Savage P, Applegate WB, Black H, et al. Effect of diuretic-based antihypertensive treatment on cardiovascular disease risk in older diabetic patients with isolated systolic hypertension. Systolic hypertension in the elderly program cooperative research group. JAMA 1996;276:1886-92.

50 Lewis EJ, Hunsicker LG, Bain RP, Rohde RD. The effect of angiotensin-converting-enzyme inhibition on diabetic nephropathy. $N$ Engl J Med 1993;329:1456-62.

51 Rodby RA, Firth LM, Lewis EJ. An economic analysis of captopril in the treatment of diabetic nephropathy. Diabetes Care 1996;19:1051-61.

52 UKPDS Group. Cost effectiveness analysis of improved blood pressure control in hypertensive patients with type 2 diabetes (UKPDS 40). $B M$ J 1998;317:720-6.

53 UKPDS Group. UK prospective diabetes study 16: overview of six years therapy of type 2 diabetes-a progressive disease. Diabetes 1995;44:1249-

54 Svetkey LP, Simons-Morton D, Vollmer WM, Appel LJ, Conlin PR, Ryan $\mathrm{DH}$, et al. Effects of dietary patterns on blood pressure: subgroup analysis of the dietary approaches to stop hypertension (DASH) randomized clinical trial. Arch Intern Med 1999;159:285-93.

55 Eriksson J, Lindström J, Valle T, Aunola S, Hämäläinen H, Ilanne-Parikka $\mathrm{P}$, et al. Prevention of type II diabetes in subjects with impaired glucose tolerance: the diabetes prevention study in Finland. Diabetologia 1999;42:793-801

56 Rose G. Strategy of prevention: lessons from cardiovascular disease. $B M /$ 1981;282:1847-51

(Accepted 20 March 2000) 